\title{
The Effectiveness of a Portable Fluorescence Spectrophotometer for Early Detection of Oral Cancer
}

\author{
Katsuhiro Asaka1, Akira Fukatsu², Chiaki Komine ${ }^{2 *}$ \\ ${ }^{1}$ Laboratory Medicine for Dentistry, Graduate School of Dentistry at Matsudo, Nihon University School of Dentistry at Matsudo, \\ Matsudo, Japan \\ ${ }^{2}$ Department of Laboratory Medicine and Dentistry for the Compromised Patient, Nihon University School of Dentistry at Matsudo, \\ Matsudo, Japan \\ Email: *komine.chiaki@nihon-u.ac.jp
}

How to cite this paper: Asaka, K., Fukatsu, A. and Komine, C. (2022) The Effectiveness of a Portable Fluorescence Spectrophotometer for Early Detection of Oral Cancer. Open Journal of Stomatology, 12, 20-31. https://doi.org/10.4236/ojst.2022.121003

Received: December 24, 2021

Accepted: January 23, 2022

Published: January 26, 2022

Copyright (c) 2022 by author(s) and Scientific Research Publishing Inc. This work is licensed under the Creative Commons Attribution International License (CC BY 4.0).

http://creativecommons.org/licenses/by/4.0/

\begin{abstract}
Purpose: To investigate whether photodynamic diagnosis (PDD) using a portable fluorescence spectrophotometer (FC-1) can easily and objectively discriminate between normal and tumor cells at the dental chairside, and to further compare it with PDD that requires speculum examination by focusing on protoporphyrin IX (PPIX). Methods: Three cell lines (2 human oral squamous cell carcinoma-derived cell lines, HSC-2 and HSC-3 cells, and oral keratinocytes, HOK cells) were cultured. 5-Aminolevulinic acid hydrochloride (5-ALA) and deferoxamine mesylate (DFO) were mixed in DMEM, and the mixture was set to Control (DMEM only) and PDD (5-ALA+DFO) groups. And then, a fluorescence was measured under room temperature (RT) and $37^{\circ} \mathrm{C}$ (Incubation) by using FC- 1 . In this study, the two conditions were combined with the Control and PDD groups to form the Control/RT, Control/Incubate, $\mathrm{PDD} / \mathrm{RT}$, and $\mathrm{PDD} /$ Incubate groups. Additionally, the amount of singlet oxygen $\left({ }^{1} \mathrm{O}_{2}\right)$ generated by irradiation with $405 \mathrm{~nm}$ LED was measured using electron spin resonance spectroscopy to detect PPIX in the cell supernatant after 24 hours. Results: In HSC-2 and HSC-3, the fluorescence intensity values increased significantly at 2 hours between the Control/RT and $\mathrm{PDD} / \mathrm{RT}$ groups. In addition, there was a significant difference between HSC-2 and HSC-3 compared to HOK. In all cell lines, the fluorescence intensity values of the PDD/Incubate group were significantly higher than those of the $\mathrm{PDD} /$ Control group. The amount of ${ }^{1} \mathrm{O}_{2}$ generated by $405 \mathrm{~nm}$ LED irradiation was higher in the cell supernatants of all cell lines in the order of Control/RT $<$ Control/Incubate $<\mathrm{PDD} / \mathrm{RT}<\mathrm{PDD} /$ Incubate group, and HSC-3 in the $\mathrm{PDD} /$ Incubate group showed a significant increase compared to $\mathrm{HOK}$.
\end{abstract}


Conclusion: It is suggested that PDD using FC-1 can clearly distinguish between normal cells and tumor cells in vitro studies using cell lines at 2 hours under $37^{\circ} \mathrm{C}$, and it can detect not only intracellular PPIX, but also extracellular PPIX.

\section{Keywords}

Photodynamic Diagnosis, Portable Fluorescence Spectrophotometer, Oral Cancer, Protoporphyrin IX

\section{Introduction}

Cancer of the oral cavity and pharyngeal region causes approximately 8,000 deaths per year in Japan, and the number of deaths has tripled over the past 30 years [1]. As Japan becomes a super-aged society, the number is expected to continue to increase. The prognosis for advanced oral cancer has a significant impact on the quality of life of the patient, not only in terms of functions such as chewing and swallowing, but also in terms of aesthetics, such as facial appearance; therefore, early detection is very important. Traditionally, oral cancer has been considered to be an area that can be seen directly and is easy to detect. However, the detection and diagnosis of oral cancer are relatively easy for the general dental clinician if the disease is advanced, but it is difficult to diagnose oral mucosal diseases, including oral potentially malignant disorders, in the early stages, because the clinical pictures of early-stage oral cancer and oral mucosal diseases are very similar [2]. Visual inspection and digital palpation are mainly effective in detecting oral cancer [3], and various other examinations are also performed [4] [5] [6] [7] [8]. However, these methods rely on the clinical experience of dentists, and there are still few objective screening methods that do not rely on experience. For the early detection of oral cancer, it is very important to establish an objective diagnostic method that is less prone to disparities among medical professionals.

Recently, objective diagnostic methods such as fluorescence observation systems [2] [9] [10] and photodynamic diagnosis (PDD) [11] [12] [13] [14] [15] using fluorescence have attracted significant attention for oral cancer diagnosis. The former is based on the autofluorescent properties of healthy organisms, such as cofactors (flavin adenine dinucleotide) in the mucosal epithelium and collagen cross-linking in the stroma, and the latter is based on fluorescence microscopy of the fluorescence of protoporphyrin IX (PPIX), which accumulates in tumor cells. However, we consider even these methods to be semi-quantitative, with subjective evaluation of the surgeon or speculum examiner playing a large role. Our laboratory has been conducting research on PDD in order to pursue further objective quantitative diagnosis [14] [15]. In other words, we proposed to take up 5-aminolevulinic acid hydrochloride (5-ALA) in scraped cells and quantify the fluorescence level of PPIX, which is metabolized in the cells, in a fluorescent plate reader for diagnosis. In addition, the objective evaluation by 
quantifying the fluorescence intensity using a fluorescence plate reader is useful for early detection of oral cancer and may also be applied to mass screening, since many samples can be measured at once. However, individual examinations at general dental clinics are also essential to reduce the mortality rate through early detection of oral cancer. For this purpose, it is desirable to develop a PDD method that enables simple, rapid, and objective evaluation with examination equipment that can be installed in clinic facilities with limited space.

The purpose of this study was to investigate whether PDD using a portable fluorescence spectrophotometer can easily and objectively discriminate between normal and tumor cells at the chairside, and to further compare it with the conventional PDD that requires speculum examination by focusing on PPIX.

\section{Materials \& Methods}

1) Cell culture

HSC-2 and HSC-3 cells were obtained from RIKEN (Tokyo, Japan) as human oral squamous cell carcinoma-derived cell lines, and oral keratinocytes (HOK) were obtained from ScienCell Research Laboratories (Carlsbad, CA, USA) as normal human primary cultured cells. The HSC-2 and HSC-3 cells were grown in Dulbecco's Modified Eagle's Medium (DMEM, Sigma-Aldrich, St. Louis, MO, USA) supplemented with $10 \%$ fetal bovine serum (FBS) and $100 \mu \mathrm{g} / \mathrm{ml}$ penicillin streptomycin (Gibco, St. Louis, MO, USA) in 10-cm-diameter dishes. HOK cells were cultured in oral keratinocyte medium (ScienCell Research Laboratories) with $5 \mathrm{ml} \mathrm{HOK}$ growth supplement and $5 \mathrm{ml}$ penicillin/streptomycin. The cultures were then maintained in an atmosphere of $5 \% \mathrm{CO}_{2}, 90 \% \mathrm{~N}_{2}$, and $5 \% \mathrm{O}_{2}$ at $37^{\circ} \mathrm{C}$. The culture media were changed every 3 days.

2) Reagents and a portable fluorescence spectrophotometer

5-ALA (MW: 167.6) and deferoxamine mesylate (DFO, MW: 656.8) were purchased from Neopharma Japan (Tokyo, Japan) and Cayman Chemical Company (Ann Arbor, MI, USA), respectively. Following our previous reports [14] [15], 5-ALA was dissolved in DMEM and used as a porphyrin derivative at a final concentration of $2 \mathrm{mM}$, and then DFO, which is an iron chelating agent, was added at a final concentration of $5 \mathrm{mM}$. The 2,2,6,6-tetramethyl-4-piperidone (4-oxo-TMP) was purchased from FUJIFILM Wako Pure Chemical Industries, Ltd. (Osaka, Japan). All other reagents were analytical grade.

A portable fluorescence spectrophotometer used FC- $1^{\circledR}$ (Tokai Optical Co., Ltd., Aichi, Japan). It is a straightforward configuration that enables simple realization of the principle of fluorescence measurement itself. In brief, the sample in the cell is irradiated with the excitation light $(\lambda=405 \mathrm{~nm})$, and the emitted fluorescence wavelength $(\lambda=630 \mathrm{~nm})$ is detected by the photodetector. The excitation light scattered or reflected in the direction of the photodetector is then passed through the fluorescence filter, and only the fluorescence wavelength is quantified and detected.

3) Fluorescence intensity measurement using FC-1 
When the HSC-2, HSC-3, and HOK cells reached confluence, the cells were detached with $0.05 \%$ trypsin $-0.53 \mathrm{mmol} / \mathrm{l}$ EDTA.4Na (Wako, Osaka) solution and passaged in culture dishes. After centrifugation, the cells were adjusted to 5 $\times 10^{5}$ cells $/ \mathrm{ml}$ in a hemocytometer using trypan blue. Then, the experimental groups with 5-ALA+DFO and DMEM only were designated as the PDD and Control groups, respectively. For $5 \times 10^{5}$ cells of each cell line in the centrifuge tube, $2-\mathrm{ml}$ of each reagent were added, stirred, and stored at room temperature $\left(\mathrm{RT}, 22^{\circ} \mathrm{C} \pm 0.5^{\circ} \mathrm{C}\right.$ ), shielded from light in the atmosphere. The fluorescence intensity was measured for 6 hours using a FC- 1 at 2 hours intervals after the start of action. In short, the samples were transferred from the centrifuge tube to the FC-1 measurement cell and measured every 2 hours. After each measurement, the sample was returned to the centrifuge tube, and the process was repeated. Additionally, the effects of different metabolic environments on fluorescence intensity were investigated.

The experimental groups were placed in an incubator $\left(37^{\circ} \mathrm{C} \pm 0.5^{\circ} \mathrm{C}\right)$ under the same conditions (incubate condition), and fluorescence intensity was measured and compared with that obtained at RT (RT condition). In this study, the two conditions were combined with the Control and PDD groups to form the Control/RT, Control/Incubate, PDD/RT, and PDD/Incubate groups.

4) Detection of singlet oxygen from excited-PPIX in cell supernatant by 405nm-LED irradiation

The amount of generated singlet oxygen $\left({ }^{1} \mathrm{O}_{2}\right)$ was measured using electron spin resonance (ESR) spectroscopy (JES FA-200, JEOL, Tokyo, Japan). The culture supernatants of the Control/RT, Control/Incubate, PDD/RT, and $\mathrm{PDD} /$ Incubate groups of each cell line 24 hours after the start of metabolism were collected after centrifugation. After collection, the cell supernatant (150 $\mu \mathrm{l})$ and 4-oxo-TEMP $(150 \mu \mathrm{l})$ were mixed in one well of a 96-well plate and immediately irradiated with a 405-nm LED for 60 seconds. Subsequently, the mixture was transferred into a flat quartz cell and then measured using an ESR spectrometer.

The ESR measurements were conducted under the following conditions: magnetic field, $335 \pm 5 \mathrm{mT}$; modulation width, $0.1 \mathrm{mT}$; time constant, 0.1 seconds; microwave power, $4.00 \pm 0.05 \mathrm{~mW}$; sweep width, $5 \mathrm{mT}$; sweep time, 2 minutes; and amplitude, 100 . Signal intensity was normalized by $\mathrm{MnO}$ marker, and the RI value was calculated [16].

5) Statistical analysis

Statistical analyses were performed with IBM SPSS Statistics ver.22 (IBM, Armonk, NY, USA). The relative fluorescence intensity of HSC-2 and HSC-3 cells against HOK cells in RT, and the RI value obtained by LED irradiation of the cell supernatant of each group were analyzed by Dunnett's $t$-test. The fluorescence intensity obtained from Control/RT and PDD/RT groups, or PDD/RT and $\mathrm{PDD} /$ Incubate groups were analyzed by Student's $t$-test.

The level of significance was set at $1 \%$ for all analyses. 


\section{Results}

Figure 1 shows the fluorescence intensity values of each cell line in the Control/RT and PDD/RT groups. In all cell lines, the fluorescence intensity values of the Control/RT and PDD/RT groups increased in a 5-ALA metabolism time-dependent manner. In HOK cells, the fluorescence intensity value of 5 -ALA metabolic initiation was significantly lower in the PDD/RT group than in the Control/RT group at 2 hours, but was significantly higher at 4 hours $(\mathrm{p}<$ $0.01)$. At 6 hours, there was no significant difference between them $(p=0.4)$ (Figure 1(a)). On the other hand, in HSC-2 and HSC-3 cells, the fluorescence intensity values of the PDD/RT group showed a significant increase compared to that of the Control/RT group at all times $(\mathrm{p}<0.01)$ (Figure 1(b), Figure $1(\mathrm{c})$ ).
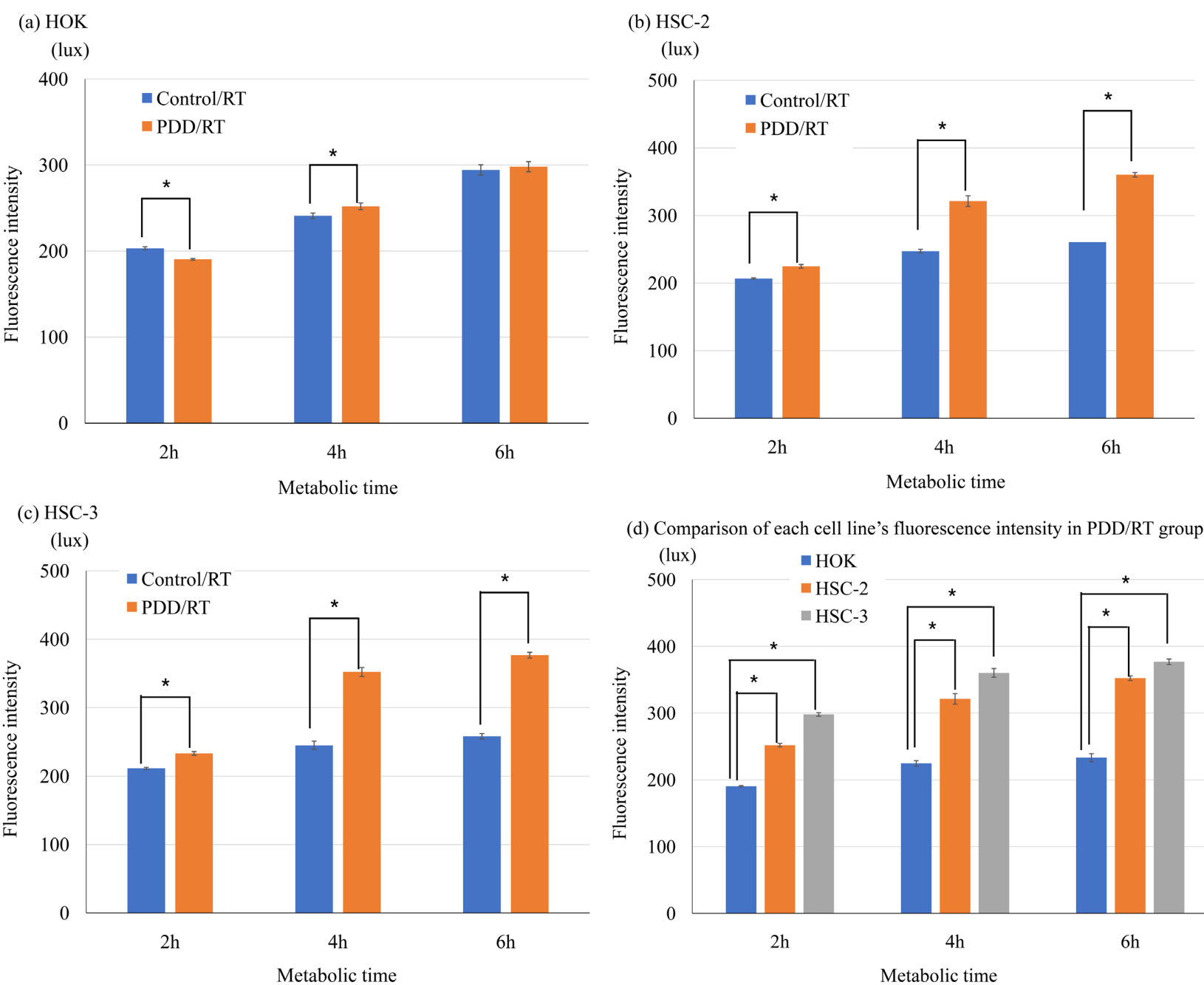

(d) Comparison of each cell line's fluorescence intensity in PDD/RT group

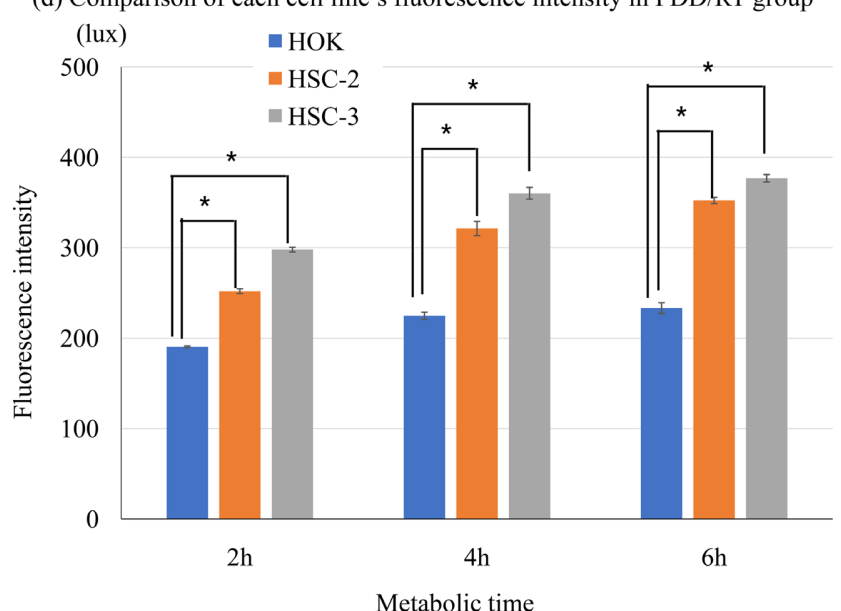

Figure 1. The fluorescence intensity values of each cell line in the Control/RT and PDD/RT groups (figure caption). (a) Comparison of fluorescence intensity between Control/RT and PDD/RT groups in HOK cells, (b) comparison of fluorescence intensity between Control/RT and PDD/RT groups in HSC-2 cells, (c) comparison of fluorescence intensity between Control/RT and $\mathrm{PDD} / \mathrm{RT}$ groups in HSC-3 cells and (d) multiple comparisons of each cell line in the PDD/RT group. The $\mathrm{x}$ - and $\mathrm{y}$-axes indicate the metabolic time and fluorescence intensity value (lux), respectively. Figure 1(a), Figure 1(b), or Figure 1(c) were analyzed by Student's $t$-test, and Figure 1(d) was analyzed by Dunnett's $t$-test. In all analyses, the significance level of the P-value was set at $1 \%$. Data are expressed as means \pm SD of multiple experimental replicates $(n=4)$. 
Furthermore, a comparison among cell lines in the PDD/RT group showed a significant difference in their fluorescence intensities between $\mathrm{HOK}$ and oral squamous carcinoma (HSC-2 and HSC-3) in all incubation times $(\mathrm{p}<0.01)$ (Figure 1(d)).

Figure 2 showed a comparison of the fluorescence intensity values obtained from the PDD/RT and PDD/Incubate groups of each cell line. HOK showed no significant differences at 2, 4 and 6 hours $(\mathrm{p}>0.01$ ) (Figure 2(a)). In contrast, the fluorescence intensity values of HSC-2 and HSC-3 cells increased significantly more in the $\mathrm{PDD} / \mathrm{Incubate}$ group than in the $\mathrm{PDD} / \mathrm{RT}$ group in all groups
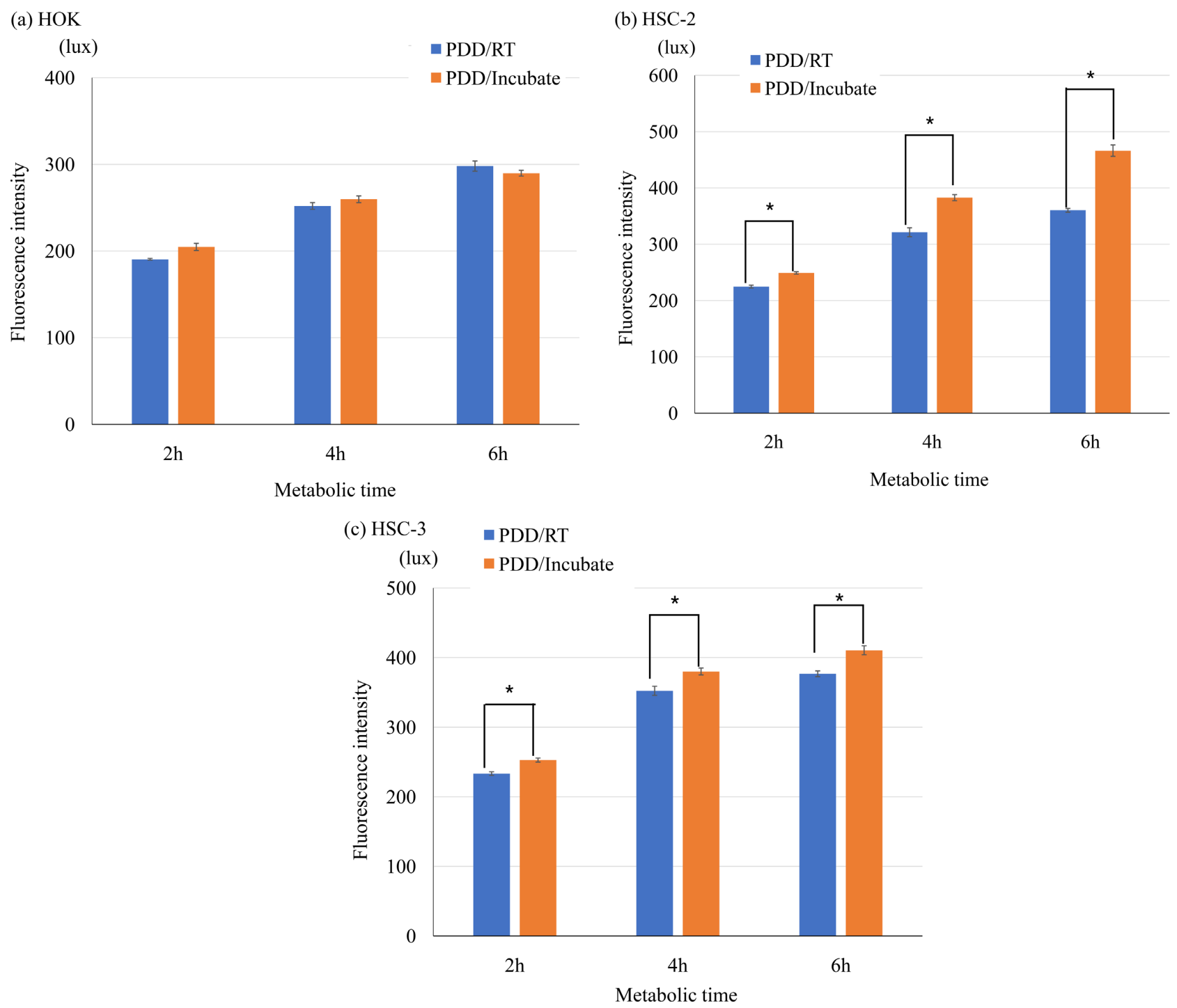

Figure 2. Comparison of the fluorescence intensity values obtained in the PDD/RT and PDD/Incubate groups of each cell line. (figure caption) (a) Comparison of fluorescence intensity between PDD/RT and PDD/Incubate groups in HOK cells, (b) comparison of fluorescence intensity between PDD/RT and PDD/Incubate groups in HSC-2 cells and (c) comparison of fluorescence intensity between PDD/RT and PDD/Incubate groups in HSC-3 cells. The $\mathrm{x}$ - and y-axes indicate the metabolic time and fluorescence intensity value (lux), respectively. The fluorescence intensity values obtained from the PDD/RT and PDD/Incubate groups were analyzed by Student's $t$-test, and the significance level of the P-value was set at $1 \%$. Data are expressed as means \pm SD of multiple experimental replicates $(n=4)$. 
the start of 5-ALA metabolism ( $\mathrm{p}<0.01$ ) (Figure 2(b), Figure 2(c)).

Figure 3 showed the typical ESR-spectra and RI values. The typical ESR spectrum is a 1:1:1 triplet signal characteristic of 4-oxo-TEMPO having a hyperfine splitting constant $(\mathrm{aN}=1.608 \mathrm{mT})$, which is produced when ${ }^{1} \mathrm{O}_{2}$ reacts with 4-oxo-TEMP. The amplitudes of the spectra increased in the order Control/RT < Control/Incubate $<\mathrm{PDD} / \mathrm{RT}<\mathrm{PDD} /$ Incubate group. Furthermore, when the RI values of each cell line were compared for each group, HSC-3 cells showed significantly higher RI values than HOK cells only in the PDD/Incubate group ( $\mathrm{p}<$ $0.01)$. No significant difference was observed in the other groups.

\section{Discussion}

With the advent of a super-aging society, the importance of prevention, examination, diagnosis, and treatment of cancer and lifestyle-related diseases is increasing. The importance of these issues is also understood in the field of dental medicine, and many reports or protocols have been published on dental caries [17], periodontal disease [18], oral cancer [19], and the relationship between systemic diseases and dental diseases [20] [21] [22] [23]. These results clearly demonstrate that the diversity of examinations and diagnoses has expanded the options for dental treatment, including prevention.

Our laboratory has been investigating a diagnostic method applying PDD that is safe and secure and enables all dentists to detect oral cancer in its early stages

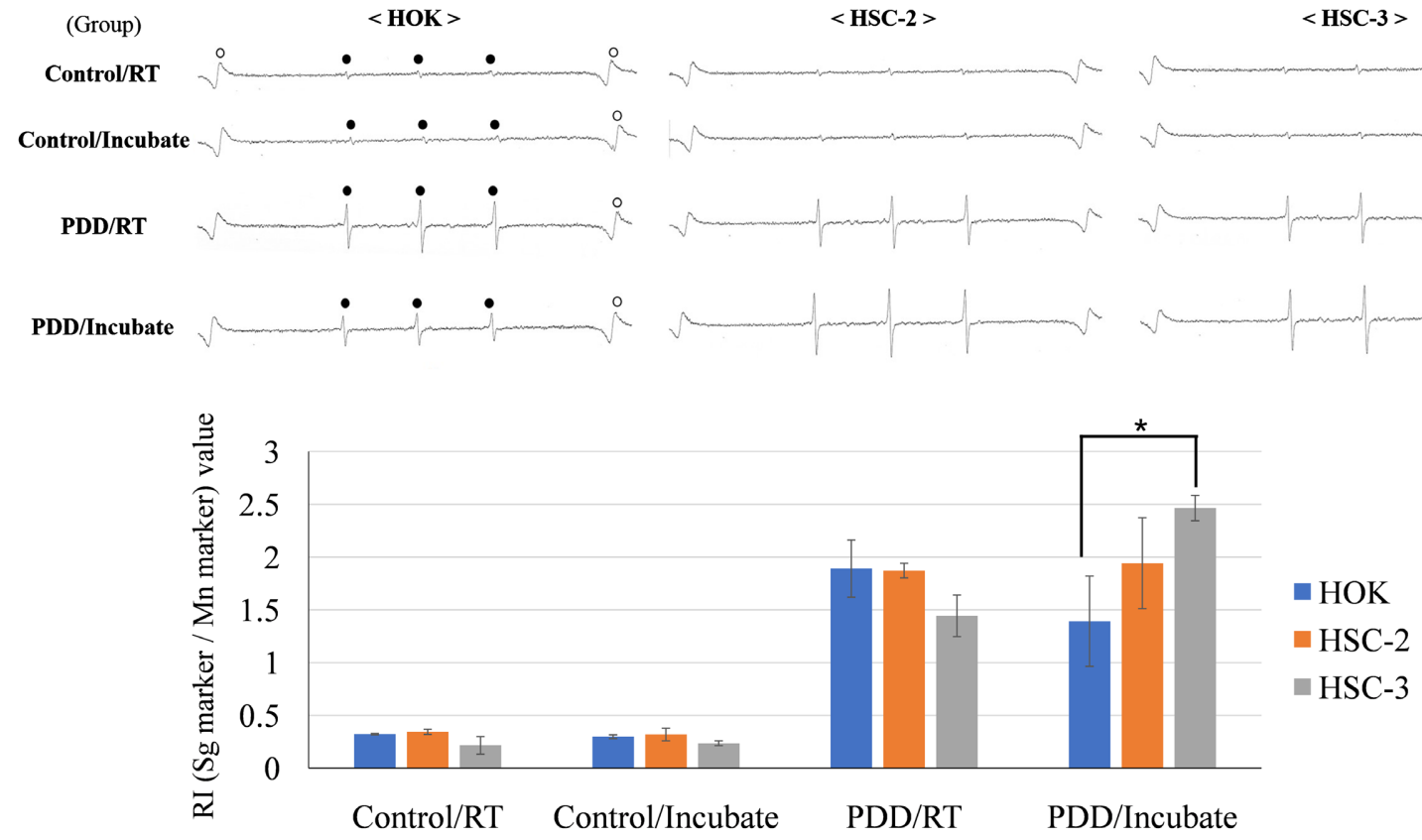

Figure 3. Comparison of the ESR-spectra obtained after 405-nm-LED irradiation and the RI-value (figure caption). Typical ESR-spectra of 405-nm-LED irradiation for 60 seconds to supernatants of HOK, HSC-2, and HSC-3 cells after 24 hours of metabolic initiation. The white and black circles indicate the $\mathrm{Mn}^{2+}$ marker and the nitroxide radical, respectively. The $\mathrm{x}$ and y-axes indicate the experimental groups and RI value, respectively. The RI value of each cell line obtained by LED irradiation of the cell supernatant of each group were analyzed by Dunnett's $t$-test, and the significance level of the P-value was set at $1 \%$. Data are expressed as means \pm SD of multiple experimental replicates $(n=3)$. 
[14] [15]. We found that accumulation of PPIX in cells using 5-ALA and DFO, an iron chelator, could clearly distinguish normal cells from tumor cells using a fluorescent plate reader. Furthermore, this method could also be achieved with the number of cells safely scraped from the brush reported by Ikawa et al. [24]. However, the fluorescence plate reader is only suitable for mass examinations, but not for general dentists. In the present study, we investigated whether a portable fluorescence detector, which is considered to be appropriate for general dentists, can distinguish between normal cells and tumor cells in oral tissue.

First, the measured fluorescence intensities of the Control/RT and PDD/RT groups for each cell line were compared. In HSC-2 and HSC-3 cells, there was a significant increase in the fluorescence intensity values of the PDD/RT group at 2 hours after the start of metabolism. In HOK cells, the PDD/RT group showed a significant increase in the fluorescence intensity value 4 hours after the start of metabolism, but the value decreased significantly after 2 hours, and there was no significant difference after 6 hours. Furthermore, when comparing HOK cells with HSC-2 and HSC-3 cells in the PDD/RT group, the fluorescence intensity values were significantly increased compared to $\mathrm{HOK}$ cells at all metabolic times after 2 hours of metabolism. The fluorescence intensity values increased in a metabolic time-dependent manner in the order of HSC-3 > HSC-2 > HOK cells. This is considered to be largely due to the differences in differentiation. HSC-2 cells are a highly differentiated cell line, but HSC-3 cells are a poorly differentiated cell line, suggesting that the fluorescence intensity is higher in poorly differentiated cells, which is consistent with the report by Uekusa et al. [25]. On the other hand, it has been reported that fluorescence intensity is higher in highly differentiated cell lines, but different opinions [14] [15] have been expressed depending on the cell differentiation, and further studies are needed. Since the fluorescence intensity of HOK cells increases in a time-dependent manner, it is considered to be homeostatically accumulated during the porphyrin metabolism process when 5-ALA is metabolized to PPIX. In addition, the reason for the increase in fluorescence intensity in the PDD/RT group of this study is considered to be that 5-ALA is metabolized to PPIX, and the iron chelator DFO inhibits ferrochelatase and the conversion of PPIX to heme, resulting in an increase in intracellular PPIX and an increase in fluorescence intensity by excitation [25].

Next, the effect of different metabolic environments, especially temperature, on fluorescence intensity was investigated. The fluorescence intensity values of HSC-2 and HSC- 3 cells showed a significantly higher increase in the PDD/Incubate group than in the PDD/RT group. It is thought that this is due to enzyme activity and mitochondrial function. Numerous enzymes such as ferrochelatase [26] [27], ALA dehydratase [28], uroporphyrinogen III decarboxylase [28] or porphobilinogen deaminase [28], are thought to be involved in the synthesis of PPIX. These enzymes then function in the cytoplasm or mitochondria. These enzymes have an optimum temperature, and since all of the above enzymes are active in vivo, it is suggested that the optimum temperature for these enzymes is around $37^{\circ} \mathrm{C}$. 
The mitochondria themselves are also active in their metabolic functions at around $37^{\circ} \mathrm{C}$. Additionally, regarding the effect of temperature on the accumulation of PPIX in dermatology, Asta et al. [29] reported that lowering the skin temperature to $28^{\circ} \mathrm{C}-32^{\circ} \mathrm{C}$ reduced the accumulation of PPIX by $1 / 3$ to $1 / 2$, and that increasing the temperature of the target tissue can enhance the accumulation of PPIX. The present results are similar, suggesting that incubation at $37^{\circ} \mathrm{C}$ is more clearly distinguishable when measuring fluorescence intensity using FC-1.

Finally, PPIX was detected indirectly by irradiating the cell supernatant after 24 hours with a 405-nm LED. In brief, the mechanism of PPIX extracellular efflux by ABCG2, a cell membrane transporter, or by exocytosis has been reported [30]. PPIX has an optical absorption spectrum with five peaks between 400 and $650 \mathrm{~nm}$ [31]. Therefore, PPIX changes to a triplet state and transfers energy to nearby oxygen atoms in the ground state to produce ${ }^{1} \mathrm{O}_{2}$ by absorbing a photon upon light irradiation. Applying this mechanism, we attempted to detect PPIX indirectly by trapping ${ }^{1} \mathrm{O}_{2}$ using ESR, since the generation of ${ }^{1} \mathrm{O}_{2}$ can be inferred to be due to the excited-PPIX. The result showed that HSC-3 cells, which had the highest accumulation of PPIX in the cells had the highest RI value, as well as HSC-2 and HOK cells in that order. Cell lines with a high accumulation of PPIX are thought to have a similarly high extracellular export of PPIX, and a diagnostic method using FC-1 can detect not only intracellularly accumulated PPIX, but also extracellularly discharged PPIX.

In consideration of these factors, objective evaluation by quantifying fluorescence intensity using FC-1 is thought to have a significant advantage over the conventional PDD using a fluorescence microscope. The problems of conventional PDD compared to PDD using FC-1 are as follows: 1) subjective evaluation by the naked eye, which is affected by the intensity of fluorescence $[32] ; 2)$ the amount of excitation light is not constant, which means that the fluorescence intensity is affected by the focal distance from the microscope and the angle to the optical axis of the surgical field [33]; and 3) must target only PPIX accumulated in the cell. On the other hand, a common problem of conventional PDD and PDD using FC-1 is that the blood on the surgical field surface blocks the excitation light [34]. In addition, this study was an in vitro study using a cell line, and in fact, there are limitations in mentioning the effect of PDD using FC-1 because of the mixture of normal and tumor cells. In the future, it will be necessary to investigate whether PDD can be diagnosed with cells taken from actual tumor tissues.

\section{Conclusion}

The results of the present study suggest that PDD using FC-1 can clearly distinguish between normal cells and tumor cells in in vitro studies using cell lines at 2 hours under $37^{\circ} \mathrm{C}$, and it can detect not only intracellular PPIX, but also extracellular PPIX. 


\section{Acknowledgements}

This work was supported by JSPS KAKENHI Grant Number 19K19076 and 20K10256.

The authors would like to express their deepest gratitude to the optical products division of Tokai Optics Co., Ltd. (Aichi, Japan), Iwano Industries Co., Ltd. (Tokyo, Japan), and TAO Planning Co., Ltd. (Chiba, Japan) for providing the data and advice necessary for this study.

\section{Conflicts of Interest}

The authors declare no conflicts of interest regarding the publication of this paper.

\section{References}

[1] National Cancer Center, Center for Cancer Control and Information Service. https://ganjoho.jp/reg_stat/statistics/stat/cancer/3_oral.html

[2] Akira, K., Ken-Itirou, U., Shun, T., Mira, K., Takeshi, N., Takashi, Y., Ryo, T. and Takahiko, S. (2012) Application of Fluorescence Visualization Technology to the Screening of Oral Mucosal Diseases. Journal of Japanese Society for Laser Dentistry, 23, 142-146.

[3] Tanya, W., Joseph, LY, L., Paul, B., et al. (2013) Clinical Assessment to Screen for the Detection of Oral Cavity Cancer and Potentially Malignant Disorders in Apparently Healthy Adults. Cochrane Database of Systematic Reviews. https://www.cochranelibrary.com/cdsr/doi/10.1002/14651858.CD010173.pub2/epdf /full

[4] Mehrotra, R., Hullmann, M., Smeets, R., Reichert, T.E. and Driemel, O. (2009) Oral Cytology Revisited. Journal of Oral Pathology and Medicine, 38, 161-166. https://doi.org/10.1111/j.1600-0714.2008.00709.x

[5] Li, Y.N., Lu, R., Zhang, J. and Zhou, G. (2018) Inter-and Intra-Observer Agreement on The Judgment of Toluidine Blue Staining for Screening of Oral Potentially Malignant Disorders and Oral Cancer. Clinical Oral Investigations, 23, 1709-1714. https://doi.org/10.1007/s00784-018-2595-7.

[6] Massimo, P., Alberta, L., Edoardo, B., Felice, R.G. and Rosario, S. (2010) Use of Lugol's Iodine in Oral Cancer Diagnosis: An Overview. Oral Oncology, 46, 811-813. https://doi.org/10.1016/j.oraloncology.2010.07.013

[7] Zohaib, K., Muhammad, S.Z., Rabia, S.K., Shariq, N., Paul, D.S. and Ihtesham, U.R. (2018) Role of Salivary Biomarkers in Oral Cancer Detection. Advances in Clinical Chemistry, 86, 23-70. https://doi.org/10.1016/bs.acc.2018.05.002

[8] Lalima, T., Omar, K. and Camile, S.F. (2020) Optical Fluorescence Imaging in Oral Cancer and Potentially Malignant Disorders: A Systematic Review. Oral Diseases, 26, 491-510. https://doi.org/10.1111/odi.13071

[9] Ekaterina, S., Reza, A.N., Adel, E.N., Rhonda, J., Ann, G. and Rebecca, R.K. (2004) Vision Enhancement System for Detection of Oral Cavity Neoplasia Based on Autofluorescence. Head \& Neck, 26, 205-215. https://doi.org/10.1002/hed.10381

[10] Takamichi, M., Ayaka, K. and Takahiko, S. (2019) The Utility of Optical Instrument "ORALOOK ${ }^{\circledast ”}$ in the Early Detection of High-risk Oral Mucosal Lesions. Anticancer Research, 39, 2519-2525. https://doi.org/10.21873/anticanres.13373 
[11] Adriana, C. (2020) Clinical Uses of 5-Aminolaevulinic Acid in Photodynamic Treatment and Photodetection of Cancer: A Review. Cancer Letters, 490, 165-173. https://doi.org/10.1016/j.canlet.2020.06.008

[12] Seiko, T. and Kazuhito, S. (2020) Non-Invasive Diagnostic System Based on Light for Detecting Early-Stage Oral Cancer and High-Risk Precancerous Lesions-Potential for Dentistry. Cancers, 12, Article No. 3185. https://doi.org/10.3390/cancers12113185.

[13] Martin, O.D., Adam, D., Miles, P., Ogden, G.R., McLaren, S. and Carol, R.G. (2008) Detection of Mucosal Abnormalities in Patients with Oral Cancer Using a Photodynamic Technique: A Pilot Study. British Journal of Oral and Maxillofacial Surgery, 46, 6-10. https://doi.org/10.1016/j.bjoms.2007.05.009.

[14] Omori, H. and Komine, C. (2021) Development of a Photodynamic Diagnosis Method for Oral Squamous Cell Carcinoma Using 5-Aminolevulinic Acid and a Luminescence Plate Reader. Open Journal of Stomatology, 11, 325-340. https://doi.org/10.4236/ojst.2021.119029.

[15] Chiaki, K., Hiroko, O., Yuki, O., Yoshimi, K., Katsuhiro, A., Yoshinori, O., Mana, F., Osamu, T., Akira, F. and Masahiko, F. (2022) Establishment of an Objective Screening Method for Oral Malignant Tumors Using a Photodynamic Technique Involving a Fluorescence Plate Reader. Journal of Japanese Society for Evidence and the Dental Professional, in Print.

[16] Chiaki, K. and Yasuhisa, T. (2013) A Small Amount of Singlet Oxygen Generated via Excited Methylene Blue by Photodynamic Therapy Induces the Sterilization of Enterococcus faecalis. Journal of Endodontics, 39, 411-414. https://doi.org/10.1016/j.joen.2012.11.051

[17] Lena, N., Dan, D.M., Hadas, G.P., Efrat, A. and Shlomo, P.Z. (2018) Caries Risk Assessment Tool and Prevention Protocol for Public Health Nurses in Mother and Child Health Centers, Israel. Public Health Nursing, 35, 64-69. https://doi.org/10.1111/phn.12367.

[18] Frank, A.S. and Eva, G. (2020) The Prevention of Periodontal Disease-An Overview. Periodontology, 84, 9-13. https://doi.org/10.1111/prd.12330.

[19] Sharon, D. and Veeranjaneyulu, A. (2018) Preventive Measures in Oral Cancer: An Overview. Biomedicine \& Pharmacotherapy, 107, 72-80.

https://doi.org/10.1016/j.biopha.2018.07.114.

[20] Aminoshariae, A., Kulild, J.C., Mickel, A. and Fouad, A.F. (2017) Association between Systemic Diseases and Endodontic Outcome: A Systematic Review. Journal of Endodontics, 43, 514-519. https://doi.org/10.1016/j.joen.2016.11.008.

[21] Yoshihisa, Y. and Toru, T. (2017) The Oral Microbiome and Human Health. Journal of Oral Science, 59, 201-206. https://doi.org/10.2334/josnusd.16-0856.

[22] Fumihiro, N., Shin-Ichi, Y., Makiko, K., Akinari, S., Kiyonori, H. and Hiroshi, K. (2019) Relationship between the Quantity of Oral Candida and Systemic Condition/Diseases of the Host: Oral Candida Increases with Advancing Age and Anemia. Mycopathologia, 184, 251-260. https://doi.org/10.1007/s11046-019-00326-x.

[23] Mary, T., Kari, A.L.C. and Laura, S.M. (2014) Systemic Diseases and Oral Health. Dental Clinics of North America, 58, 797-814. https://doi.org/10.1016/j.cden.2014.07.005.

[24] Ikawa, H., Suzuki, T., Yamane, G., Katakura, Y. and Tanaka, Y. (2013) A Comparative Study of Cytobrush Sampling for Liquid based Cytology of The Oral Mucosa. The Journal of the Japanese Society of Clinical Cytology, 52, 384-385. https://doi.org/10.5795/jjscc.52.384 
[25] Masaru, U. (2009) Fluorescence Analysis of Oral Squamous Cell Carcinoma with 5-Aminolevulinic Acid Labeling. Journal of the Japanese Stomatological Society, 76, 31-36.

[26] Hefti, M., Holenstein, F., Albert, I., Looser, H. and Luginbuehl, V. (2011) Susceptibility to 5-Aminolevulinic Acid Based Photodynamic Therapy in WHO I Meningioma Cells Corresponds to Ferrochelatase Activity. Photochemistry and Photobiology, 87, 235-241. https://doi.org/10.1111/j.1751-1097.2010.00821.x

[27] Yoshiko, O., Yuki, N., Sakihito, K., Mari, S., Hajime, M., Osamu, S., Hirofumi, M. and Shigeru, T. (2005) Mechanisms Involved in $\delta$-Aminolevulinic Acid (ALA)-Induced Photosensitivity of Tumor Cells: Relation of Ferrochelatase and Uptake of ALA to the Accumulation of Protoporphyrin. Biochemical Pharmacology, 71, 42-49. https://doi.org/10.1016/j.bcp.2005.10.019.

[28] Chang, K.P., Chang, C.S. and Sassa, S. (1975) Heme Biosynthesis in BacteriumProtozoon Symbioses: Enzymic Defects in Host Hemoflagellates and Complemental Role of Their Intracellular Symbiotes. Proceedings of the National Academy of Sciences of the United States of America, 72, 2979-2983.

[29] Asta, J., Petras, J., Olav, K., Vladimir, I. and Johan, M. (2002) Temperature Effect on Accumulation of Protoporphyrin IX after Topical Application of 5-Aminolevulinic Acid and Its Methylester and Hexylester Derivatives in Normal Mouse Skin. Photochemistry and Photobiology, 76, 452-456.

[30] Kitajima, Y., Ishii, T., Kohda, T., Ishizuka, M., Yamazaki, K., Nishimura, Y., Tanaka, T., Dan, S. and Nakajima, M. (2019) Mechanistic Study of PpIX Accumulation Using the JFCR39 Cell Panel Revealed a Role for Dynamin 2-Mediated Exocytosis. Scientific Reports, 9, Article No. 8666. https://doi.org/10.1038/s41598-019-44981-y

[31] Toshihiro, K. (2010) Effect of Laser Irradiation on Differentiation of Mesenchymal Stromal Cells. Journal of Japanese Society for Laser Dentistry, 21, 185-191. https://doi.org/10.5984/jipnsoclaserdent.21.185

[32] Yoshinaga, K. and Toshihiko, K. (2011) Unsolved Problems in 5-Aminolevulinic Acid Based Photodynamic Diagonosis: Quantification of Fluorescence and Molecular Mechanism of Porphyrin Accumulation. The Journal of Japan Society for Laser Surgery and Medicine, 32, 143-148. https://doi.org/10.2530/jslsm.32.143

[33] Tonn, J.C. and Stummer, W. (2008) Fluorescence-Guided Resection of Malignant Gliomas Using 5-Aminolevulinic Acid: Practical Use, Risks, and Pitfalls. Clinical Neurosurgery, 55, 20-26.

[34] Dirk, J.F., Egbert, G.M., Maurice, C.G.A. and Ton, G.L. (2003) Light Absorption of (Oxy-)hemoglobin Assessed by Spectroscopic Optical Coherence Tomography. Optics Letters, 28, 1436-1438. https://doi.org/10.1364/OL.28.001436 